\title{
A importância das condições higiênico-sanitárias em abatedouros: Uma revisão de literatura
}

The importance of hygienic and sanitary conditions in slaughterhouses: A literature review

La importancia de las condiciones higiénicas y sanitarias en los mataderos: Una revisión de la

\section{literatura}

Damaris Alves dos Santos

ORCID: https://orcid.org/0000-0001-7516-6871

Universidade de Vassouras, Brasil

E-mail: damarisvet@hotmail.com

Gabriela Vieira do Amaral

ORCID: https://orcid.org/0000-0003-3817-8122

Universidade de Vassouras, Brasil

E-mail: gabriela.vda@hotmail.com

Fabio Sartori

ORCID: https://orcid.org/0000-0003-0752-4758 Universidade de Vassouras, Brasil E-mail: sartori.f@uol.com.br

Jessica do Vale Simas

ORCID: https://orcid.org/0000-0002-1372-496X Universidade de Vassouras, Brasil E-mail: jeh_simas@hotmail.com

\begin{abstract}
Resumo
Manter as condições higiênicas durante a produção é considerada peça chave na obtenção de alimentos inócuos. Os produtos cárneos podem ser contaminados por microrganismos durante a manipulação e o processamento. Após ter sido contaminada, a carne oferece condições para que os microrganismos se multipliquem, se tornando um potencial veiculador de bactérias patogênicas e uma ameaça à saúde do consumidor. A aplicação de programas de autocontrole como as boas práticas de fabricação, procedimento padrão de higiene operacional e análise de perigos e pontos críticos de controle são implantados com vistas a assegurar a inocuidade e a qualidade dos produtos. Por isso, é relevante avaliar as condições higiênicas e sanitárias dos estabelecimentos através do uso do checklist e coleta de amostras por meio do $s w a b$, e por meio das amostras é realizada a identificação de microrganismos indicadores como mesófilos aeróbios, enterobactérias e coliformes totais, que vão refletir as condições higiênicas e sanitárias do local e do produto.
\end{abstract}

Palavras-chave: Contaminação; Carnes; Alimento seguro.

\begin{abstract}
Maintaining hygienic conditions during production is considered a key part in obtaining innocuous food. Meat products can be contaminated by microorganisms during handling and processing. After being contaminated, the meat offers conditions for microorganisms to multiply, becoming a potential to convey pathogenic bacteria and a threat to consumer health. The application of self-control programs such as good manufacturing practices, standard operating hygiene procedure and hazard analysis and critical control points are implemented to ensure the safety and quality of products. Therefore, it is relevant to evaluate the hygienic and sanitary conditions of the establishments through the use of the checklist and sample collection through the swab, and through the samples is performed the identification of indicator microorganisms such as aerobic mesophiles, enterobacteria and total coliforms, which will reflect the hygienic and sanitary conditions of the site and product.
\end{abstract}

Keywords: Contamination; Meats; Safe food.

\section{Resumen}

Mantener las condiciones higiénicas durante la producción se considera una parte clave en la obtención de alimentos inocuos. Los productos cárnicos pueden estar contaminados por microorganismos durante la manipulación y el procesamiento. Después de estar contaminada, la carne ofrece condiciones para que los microorganismos se multipliquen, convirtiéndose en un potencial para transmitir bacterias patógenas y una amenaza para la salud del consumidor. La aplicación de programas de autocontrol tales como buenas prácticas de fabricación, procedimiento de higiene operativa estándar y análisis de riesgos y puntos críticos de control se implementan para garantizar la seguridad y la calidad de los productos. Por lo tanto, es pertinente evaluar las condiciones higiénicas y sanitarias de los establecimientos mediante el uso de la lista de verificación y la recogida de muestras a través del hisopo, y a través 
de las muestras se realiza la identificación de microorganismos indicadores como mesofífilos aeróbicos, enterobacterias y coliformes totales, que reflejarán las condiciones higiénicas y sanitarias del sitio y el produto.

Palabras clave: Contaminación; Carnes; Comida segura.

\section{Introdução}

Os produtos de origem animal são de grande relevância para a saúde humana, sendo rica em proteínas, minerais como zinco, ferro e vitaminas, principalmente a cianocobalamina (vitamina B12) (Mateus et al., 2017). Sua forma nutricional possui alguns fatores que são essenciais na construção e manutenção de tecidos (Garnett, 2013).

No Brasil, a carne mais consumida é a de frango, estando em segundo lugar o consumo de carne bovina, seguida pela carne suína ocupando a terceira posição (Silva et al., 2019).

O consumo de proteína animal está relacionado com a renda e questões culturais. Nos Estados Unidos, a ordem de consumo é semelhante à observada no Brasil, com destaque para o frango. Já na China e União Europeia, temos a carne suína como mais relevante, seguida pela carne de frango e bovina, respectivamente. Portanto as condições higiênico-sanitárias no abate são de fundamental importância para assegurar a saúde dos consumidores (Alexandrino et al., 2020).

A transmissão de doenças pelo consumo de produtos de origem animal pode ser veiculada através dos animais que não apresentam condições adequadas de saúde, como os portadores de infecções, bem como pelo contato da carcaça a agentes externos que podem ser microbiológicos, físicos ou químicos (Silva et al., 2019).

O controle da saúde animal é regulamentado pela secretaria de defesa agropecuária, manejo sanitário dos rebanhos bovinos, nas granjas de suínos e de aves. E o conceito de saúde animal está envolvido com questões relacionadas às doenças dos animais, controle dos riscos na cadeia alimentar, saúde pública, proporcionando alimentos seguros e bem estar animal. O mercado consumidor e a demanda internacional exigem um sistema de produção que respeite o animal e ofereça bem estar do nascimento ao abate (Mendonça, 2019).

Nos abatedouros frigoríficos, para garantir a qualidade sanitária dos produtos de origem animal, a Secretaria de Defesa Agropecuária (SDA), que é um órgão subordinado ao Ministério da Agricultura Pecuária e Abastecimento (MAPA) e o Departamento de Inspeção de Produtos de Origem Animal (DIPOA), disciplinam a fiscalização e a inspeção industrial e sanitária de produtos de origem animal através do Regulamento de Inspeção Industrial e Sanitária de Produtos de Origem Animal (RIISPOA). Além de outros documentos norteadores, como através da portaria $\mathrm{n}^{\circ} 711$ de $1^{\circ}$ de novembro de 1995 (Brasil, 1995) que diz sobre as técnicas de instalações e de equipamentos para abate e industrialização de suínos e a portaria ${ }^{\circ}$ 210 de 10 de novembro de 1998 (Brasil, 1998) que regulamenta a inspeção tecnológica e higiênico-sanitária de carnes de aves e pela Agência Nacional de Vigilância Sanitária (ANVISA) (Sousa, 2018; Silva et al., 2019).

Em âmbito internacional, a Organização das Nações Unidas (ONU), através da Alimentação e a Agricultura (FAO) fazem a regularização de através do codex alimentarius, garantindo a execução da legislação alimentar, no estabelecimento de programas de controle de qualidade com competência e eficiência na análise de alimentos em nível nacional e internacional (Peres, 2014).

\section{Metodologia}

Trata-se de uma revisão de literatura integrativa, sendo uma pesquisa documental, de caráter qualitativo (Pereira et al., 2018), que envolveu a análise de artigos, teses e dissertações atualizadas, utilizando as seguintes plataformas digitais: Google acadêmico, portal de periódicos capes/MEC, biblioteca digital brasileira de teses e dissertações, scielo, portal de pesquisa da BVS veterinária, revista higiene alimentar e portais legislativos do Ministério da Agricultura, Pecuária e Abastecimento (MAPA) e Agência Nacional de Vigilância Sanitária (ANVISA). Sendo utilizadas as palavras chave: "higiênico-sanitário", "abatedouro", "DTAs", “alimento seguro", 'swab", ‘'checklist". 


\section{Revisão de Literatura}

\subsection{Segurança de alimentos}

A segurança dos alimentos é um assunto que vem aumentando sua importância no mundo, que preocupa governantes, indústrias e consumidores, sendo um desafio para o acesso a alimentos inócuos. A perspectiva de alimentos seguros tem como objetivo garantir que um alimento não causará dano ao consumidor através de perigos biológicos, químicos ou físicos (Barreto, 2017).

De acordo com a sua origem, os perigos podem ser físicos, químicos ou biológicos. Os perigos físicos são caracterizados pela presença de corpos estranhos como pedaços de metal, plásticos, areia, parafusos, caco de vidro. Já os perigos químicos têm como exemplos os antibióticos, defensivos agrícolas, sanitizantes e uma grande quantidade de produtos que podem contaminar o alimento. Os perigos biológicos são bactérias patogênicas e suas toxinas, parasitas e vírus, sendo os mais sérios do ponto de saúde pública, pois representam a maioria das ocorrências por doenças veiculadas por alimentos (DVA) (Guerra, 2015).

A Tabela 1, a seguir, lista alguns perigos que são transmitidos por alimentos contaminados. Embora as doenças de origem alimentar, sejam atribuídas com frequência a bactérias patogênicas, essa tabela aponta vários perigos que podem causar doenças pela ingestão de alimentos (Forsythe, 2013).

Tabela 1. Perigos associados aos alimentos.

\begin{tabular}{|c|c|c|}
\hline PERIGOS & & AGENTES \\
\hline \multirow{8}{*}{ Biológico } & \multirow{4}{*}{ Bactérias } & Clostridum botulinum \\
\hline & & Campylobacter jejuni \\
\hline & & Cepas patogênicas de E.Coli \\
\hline & & Listeria monocytogenes \\
\hline & \multirow{2}{*}{ Vírus } & Hepatite A \\
\hline & & Rotavírus \\
\hline & Protozoários & Entamoeba histolytica \\
\hline & Parasitas & Taenia solium \\
\hline \multirow{7}{*}{ Químico } & \multicolumn{2}{|c|}{ Resíduos veterinários } \\
\hline & \multicolumn{2}{|c|}{ Antibióticos } \\
\hline & \multicolumn{2}{|c|}{ Plastificantes, bisfenol A, cloreto de vinila } \\
\hline & \multicolumn{2}{|c|}{ Resíduos químicos, pesticidas (DDT) } \\
\hline & \multicolumn{2}{|c|}{ Metais tóxico, mercúrio, } \\
\hline & \multicolumn{2}{|c|}{ Substâncias proibidas } \\
\hline & \multicolumn{2}{|c|}{ Aditivos alimentares } \\
\hline & \multicolumn{2}{|c|}{ Vidro } \\
\hline & \multicolumn{2}{|l|}{ Metal } \\
\hline & \multicolumn{2}{|l|}{ Pedras } \\
\hline & \multicolumn{2}{|l|}{ Madeira } \\
\hline Físico & \multicolumn{2}{|l|}{ Plástico } \\
\hline & \multicolumn{2}{|c|}{ Parte de pragas } \\
\hline & \multicolumn{2}{|c|}{ Ossos } \\
\hline & \multicolumn{2}{|c|}{ Material de isolamento } \\
\hline
\end{tabular}

Fonte: Autores. 
A qualidade dos alimentos deve ser regularmente fiscalizada, em todas as etapas de produção, desde o abate, no decorrer do processamento, durante o armazenamento, passando pelo transporte, até a chegada ao consumidor. Com isso, a verificação da qualidade não ocorre somente no produto final (Peres, 2014).

Uma das ameaças graves para a segurança do alimento em abatedouros frigoríficos é a contaminação dos tecidos da carcaça com bactérias. A transmissão de microrganismos pode ocorrer através da contaminação cruzada, tendo como fontes superfícies e materiais contaminados, pela manipulação dos colaboradores, por conta da limpeza e desinfecção inapropriada, pelo uso de utensílios não esterilizados, pelo não cumprimento do decanso, jejum e dieta hídrica dos animais e pela perfuração do trato gastro intestinal durante o momento da evisceração (Barreto, 2017; Costa, 2017).

As zoonoses são doenças transmissíveis, comuns aos homens e aos animais e se apresentam em dois grupos. O primeiro grupo, os animais desempenham um papel essencial na presença da infecção na natureza, sendo o homem um hospedeiro acidental. No segundo grupo, tanto os animais como o homem contraem a infecção a partir das mesmas fontes de contaminação, como solo, água, animais invertebrados e plantas, no entanto, os animais não desempenham um papel essencial no ciclo de vida do agente etiológico, mas podem contribuir em graus variados para a distribuição e transmissão de infecções (Dias, 2012).

Segundo Viana et al. (2014), dentre as principais zoonoses transmitidas através de más condições higiênicas no abate se destacam a tuberculose, teníase, brucelose, salmonelose, toxoplasmose, antraz e leptospirose. Destaca-se que o risco de transmissão destas zoonoses é possível para o responsável pela manipulação do animal ao abate, quanto ao consumidor.

A contaminação microbiológica dos vários tipos de carne possibilita riscos para a saúde pública, como a ocorrência doenças transmitidas pelos alimentos (DTAs). As DTAs ocorrem após o consumo de alimentos que estejam contaminados com microrganismos, toxinas, substâncias químicas tóxicas, ou objetos perigosos ao organismo, causando sinais clínicos similares em uma ou mais pessoas. Em geral, os alimentos contaminados se apresentam com boa aparência, odor adequado e sem sinal de deterioração, pontos esses que contribuem com a ingestão (Nunes et al., 2017).

Os serviços de vigilância sanitária e epidemiológica realizam investigações das doenças veiculadas por alimentos que têm como características buscar informações sobre o número de pessoas afetadas, o aparecimento de sintomas, casos pontuais na população exposta ao risco, períodos de incubação e ocorrências graves, que podem evoluir a óbitos (Melo et al., 2018).

Mesmo com recursos tecnológicos e humanos, a eficácia da fiscalização das vigilâncias sanitárias é limitada, devido a vários fatores, como: a omissão de notificações das unidades de saúde e a negligência da população, pois os sinais clínicos iniciais provocados são brandos, como anorexia, náuseas, vômitos e/ou diarreia, acompanhadas ou não de febre, fazendo com que os acometidos não busquem assistência médica (Abreu et al., 2018).

No entanto, os casos de DTAs estão crescendo por conta de algumas variáveis como o crescimento do grupo de pessoas imunodeprimidas e as que não possuem conhecimento sobre as condições dos produtos de origem animal, em relação à produção inadequada, e à falha no controle higiênico-sanitário nos abatedouros. A grande causa das DTAs acontece por não serem executadas as normas de controle higiênico sanitário durante a manipulação e manutenção dos alimentos (Melo et al., 2018).

Uma das etapas de grande relevância nas doenças transmitidas por alimentos é a identificação do agente etiológico. A identificação do agente deve ser eficaz e fornecida em curto intervalo de tempo. Para tal, é necessário que ocorra melhorias no desempenho dos laboratórios responsáveis (Nunes et al., 2017).

De acordo com Martins e Barreto (2018), a preocupação com a qualidade dos alimentos também envolve perdas econômicas para a indústria, em virtude às alterações microbianas que surgem nos produtos. Em casos de problemas maiores com a segurança dos alimentos, a empresa pode ser penalizada com o recolhimento dos mesmos. Os danos à imagem do empreendimento podem causar perdas significativas na redução das vendas, como no valor de sua marca. 
Diante desse contexto, os consumidores estão adotando uma postura mais responsável e exigente em relação à compra dos produtos, atentando-se quanto à origem e a qualidade da matéria prima durante a cadeia de produção da carne, seja de bovinos, suínos ou aves (Silva et al., 2019). Surgindo dúvidas da população sobre qualidade, segurança e os problemas decorrentes de uma alimentação imprópria para a saúde humana são cada vez mais frequentes (Abujamra et al., 2017).

Por isso os consumidores têm um papel importante em complementar o empenho das agências de controle dos alimentos. Os conhecimentos acerca da qualidade e segurança, fazem com que a exigência aumente, levando a produção de alimentos inócuos e de boa qualidade (Fonseca et al., 2018).

\subsection{Programas de Autocontrole}

Uma maneira eficiente de manter as condições higiênico-sanitárias adequadas em um abatedouro frigorífico é a implementação de Programas de Autocontrole (PAC). Estes programas são aplicados pelos estabelecimentos, com o objetivo de diminuir as perdas econômicas e alcançar um produto com nível de 'qualidade exigido pelo mercado (Silva et al., 2019).

Por isso, programas de qualidade como as Boas Práticas de Fabricação (BPF), Procedimentos Padrão de Higiene Operacional e Pré-operacional (PPHO) e Programa de Análise de Perigos e Pontos Críticos de Controle (APPCC) vêm sendo aplicados. Esses programas têm como finalidades principais promover a higiene do ambiente, dos utensílios, dos colaboradores, dos equipamentos, verificando os pontos críticos e mantendo todo processo controlado, para que seja oferecido um alimento seguro (Oliveira \& Campos, 2015).

A execução dos Programas de Autocontrole começou nos anos 50, com as indústrias de alimentos adaptando as Boas Práticas que eram utilizadas pela atividade farmacêutica, dando uma grande guinada para melhorar e promover a produção de alimentos seguros e de qualidade (Ramos \& Vilela, 2016). Com o início das Boas Práticas de Fabricação (BPF), de acordo com as normas definidas, as indústrias começaram a controlar as contaminações cruzadas, o comportamento e a higiene do manipulador, higienização das superfícies, a água, as pragas, entre outros itens (Formigoni et al., 2017).

Nas décadas de 1980 e 1990, os organismos internacionais como a FAO e o Codex Alimentarius (Fórum Internacional de Normatização de Alimentos), passaram a indicar o sistema APPCC para as indústrias de alimentos. No Brasil, o programa foi introduzido na década de 90 pela Secretaria de Pesca (SEPES) do Ministério da Agricultura e, os Ministérios da Agricultura e Saúde possuíam portarias ordenando o uso deste sistema (Ramos \& Vilela, 2016).

Nos tópicos a seguir, serão descritos os principais Programas de Autocontrole, conhecidos também como gestão da qualidade, que são definidos como o conjunto de boas práticas utilizadas em várias áreas funcionais da indústria de produtos de origem animal, para obter-se, de forma segura e duradoura, a qualidade pretendida para o produto (Fruet et al., 2014).

\subsubsection{Boas práticas de fabricação}

No Brasil, as boas práticas de fabricação (BPF) foram normatizadas através do Regulamento Técnico sobre as Condições Higiênico-Sanitárias e de Boas Práticas de Elaboração para Estabelecimentos Elaboradores/Industrializadores de Alimentos, regidos pela Portaria n 368 do Ministério da Agricultura Pecuária e Abastecimento, de 04 de setembro de 1997, a qual apresenta como finalidade estabelecer requisitos gerais e essenciais de higiene e de boas práticas de elaboração para alimentos industrializados e elaborados para o consumo humano (Peres, 2014).

Segundo Oliveira et al. (2017), as boas práticas de fabricação são constituídas por um programa formado por um conjunto de regras e princípios, para a correta fabricação e manipulação do produto, que de maneira preventiva visa garantir a segurança do consumidor. Compreendem questões de nível sanitário, que vão desde normas de construção específicas, com o intuito de impedir a entrada de pragas, além de contribuir com a manutenção de higiene das instalações industriais, estocagem 
e transporte, atentando-se para os cuidados no cadastramento de fornecedores das matérias primas, no seu recebimento, manuseio, na elaboração e distribuição dos produtos.

Um dos pontos importantes presente na BPF diz respeito à atenção dada ao treinamento dos funcionários, os quais devem atender a diversas metas, dentre elas: diminuição de erros, aumento de motivação, envolvimento no trabalho, capacidade de resolver e prevenir problemas e melhorar a comunicação entre os envolvidos (Machado et al., 2015).

Além de melhorias das qualidades nutricionais e sensoriais dos produtos e da diminuição dos perigos, as BPF possibilitam um ambiente de trabalho mais eficaz e adequado, aperfeiçoando todo o processo produtivo (Reinehr et al., 2014).

Os principais benefícios da aplicação das BPF estão ligados à conquista de alimentos seguros, maior satisfação do consumidor, aumento da qualidade dos produtos, redução dos custos operacionais, redução dos custos decorrentes de recolhimento de produtos no mercado, diminuição em relação à repetição dos trabalhos por causa de erros e o atendimento às legislações vigentes. A adesão e manutenção das BPF são obrigatórias para dar início ao plano de Análise de Perigos e Pontos Críticos de Controle (APPCC) (Machado et al., 2015).

\subsubsection{Análise de perigos e pontos críticos de controle}

O sistema de Análise de Perigos e Pontos Críticos de Controle (APPCC) consiste em um programa preventivo que busca a produção de alimentos inócuos. Sendo baseado na aplicação de princípios técnicos e científicos, em todas as fases da produção dos alimentos (Souza et al., 2017).

O conceito HACCP, em inglês significa Hazard Analysis Critical Control, em português o sistema APPCC (Análise de Perigos e Pontos Críticos de Controle). É um programa com bases científicas e caráter sistêmico, o qual permite identificar perigos específicos e medidas para o seu controle, com objetivo de garantir a segurança do alimento (Ramos \& Vilela, 2016).

É um programa recomendado desde a década de 70 pela Food and Drug Administration - FDA, sendo indicado por World Health Organization - WHO e International Comission on Microbiological Specifications for Foods - ICMSF. Posteriormente, foi preconizado pelo Codex Alimentarius, tornando-se referência mundial no controle de qualidade e segurança alimentar (Stocco et al., 2016).

De acordo com Quintino e Rodolpho (2018), sintetiza o sistema APPCC como o grupo de ações de prevenção e controle necessários para diminuir ou eliminar os riscos de contaminação química, física ou microbiológica nos produtos. Esse sistema tem por objetivo detectar os perigos microbiológicos, físicos e químicos existentes em uma linha de produção, identificar os pontos críticos de controle (PCCs) nos quais estes perigos podem ser controlados e baseados em testes químicos, físicos e em observações visuais através dos quais a eficiência do controle possa ser monitorada.

A implantação do sistema APPCC acontece em várias etapas e os procedimentos iniciais são fundamentais, sendo necessário o comprometimento da gerência da empresa e a indicação de um profissional treinado para coordenar a implantação (Renehr et al., 2014).

No dizer de Stocco et al. (2016), o sistema APPCC deve ser implantado em doze etapas: determinação dos pontos críticos de controle; o controle de cada ponto crítico; a implantação de limites críticos para cada ponto crítico de controle, a verificação dos perigos e medidas preventivas; a descrição do produto; as ações corretivas necessárias para o produto; a identificação do uso correto do produto; as ações corretivas necessárias para o produto, à elaboração de um fluxograma para resumir o processo; a confirmação do fluxograma da etapa anterior; a formação da equipe para a fixação do sistema; os procedimentos para monitorar se o sistema está correto; um sistema de documentação e, por fim, registro das etapas anteriores.

As Boas Práticas de Fabricação (BPF) e os PPHO são quesitos que constituem a base higiênico-sanitária para implantação do sistema APPCC. Os princípios das boas práticas não podem ser desconsiderados na conceituação e 
implantação do sistema APPCC: “quando as boas práticas não são respeitadas, não há como e nem por que implantar o sistema APPCC" (Gelli, 2001 apud Oliveira, 2017).

\subsubsection{Procedimento padrão de higiene operacional}

O MAPA define o PPHO como um programa de higiene que tem por finalidade descrever de modo detalhado os procedimentos de higienização de equipamentos, ambientes, utensílios e superfícies destinados à produção de alimentos, dando importância às superfícies que entram em contato com os alimentos, visando a prevenir a contaminação cruzada e a contaminação do produto (Rodrigues, 2019).

No dizer de Valeiro et al. (2015), a Resolução № 10 de 22 de maio de 2003, determina que o plano PPHO possua pontos básicos como: condições e higiene das superfícies que estão em contato com o alimento, proteção contra contaminantes e adulterantes para o alimento, cuidado para que não ocorra com a contaminação cruzada, saúde dos colaboradores, higiene dos empregados, identificação e estocagem adequada de substâncias químicas e de agentes tóxicos, segurança da água, controle integrado de pragas e registros.

O processo de higienização é dividido em duas fases, que são a limpeza e sanitização. O procedimento de limpeza é dividido em procedimentos de pré-lavagem (remoção inicial da sujidade grosseira), lavagem com detergentes alcalinos ou ácidos (remoção de resíduos orgânicos e inorgânicos aderidos às superfícies através de esfregaço) e enxágue (remoção dos resíduos de detergentes), como descrito por Silveira et al. (2015).

A sanitização é um procedimento obrigatório que deve ser feito após a limpeza de superfícies e equipamentos, tendo como objetivo eliminar os microrganismos patogênicos e deteriorantes. Existem vários agentes sanitizantes utilizados em frigoríficos, ressaltando o emprego de compostos clorados, quartenários de amônio e iodados, ácidos e peróxido de hidrogênio, sendo que a aplicação direta ou aspergida destas substâncias sobre as superfícies ajuda a controlar o crescimento da microbiota presente, podendo inibir ou eliminar sua multiplicação e aderência (Wolf, 2017).

Segundo Barreto (2017), por causa da frequência, a higienização é dividida em higienização pré-operacional e operacional. A primeira compreende na limpeza antes do início das atividades, a segunda inclui a limpeza e a sanitização de utensílios e equipamentos durante a produção e nos intervalos entre turnos. A higiene dos funcionários que manipulam os alimentos é controlada através das barreiras sanitárias, antes da entrada nas áreas de produção.

A não realização ou deficiência do procedimento de higienização pode resultar na formação de biofilmes nas superfícies, se tornando uma potencial fonte de contaminação para os alimentos. A formação de biofilmes dificulta a higienização das superfícies (Rodrigues, 2019).

De acordo com Silveira et al. (2015), o fornecimento de água de boa qualidade é essencial para o funcionamento da indústria de alimentos, pois a água além de ser usada nos procedimentos de higienização dos equipamentos, superfícies, utensílios e para a higiene pessoal, também é utilizada na produção e transferência de calor. Para assegurar uma boa higienização na indústria de alimentos, a água deve ser livre de bactérias, impurezas e não ser dura, além de apresentar características sensoriais adequadas sendo inodora, insípida, límpida e incolor. A água pode vir de várias fontes como rios, nascentes, poços, sendo fundamental ser tratada antes do uso, na maioria dos casos.

\subsection{O uso de checklist para avaliação higiênico-sanitária nos abatedouros}

O uso de checklist é uma excelente forma de verificação das condições higiênico-sanitárias de um estabelecimento de alimentos. Esta ferramenta que permite que seja feita uma avaliação preliminar, através da observação, das condições higiênico-sanitárias do espaço. Os parâmetros avaliados são relativos às instalações, saneamento e edificações, sanitização, produção, recursos humanos, condições ambientais, controle de qualidade e de mercado (Silva et al., 2019). 
A lista de verificação avalia desde a estrutura física da empresa, até os funcionários e sua higiene pessoal. Após sua aplicação, é elaborado um plano de ação. Então, as melhorias começam a ser feitas e modificam a estrutura da indústria, desde a estrutura física, os equipamentos, a produção e, principalmente, a consciência do manipulador de alimentos (Peres, 2014).

O checklist é determinado pela Resolução RDC N. 275, de 21 de outubro de 2002, pela Agência Nacional de Vigilância Sanitária (ANVISA). Sendo composto por vários itens relacionados ao estabelecimento, que serão avaliados através de três respostas: Sim (itens conforme), Não (itens não conforme) e NO (itens não observados), os quais serão analisadas posteriormente, a título de verificação da necessidade de melhoria do local, garantindo-se, assim, a distribuição de um produto seguro para o consumidor (Dantas et al., 2017).

A seguir, na Tabela 2, podemos observar os trabalhos recentes publicados e seus resultados relevantes com relação à verificação das condições higiênico sanitárias nos estabelecimentos abatedouros a partir da utilização do checklist como ferramenta.

Tabela 2. Publicações nacionais recentes com a utilização de checklist para verificação das condições higiênico-sanitárias em abatedouros frigoríficos.

\begin{tabular}{|c|c|c|}
\hline Autor, ano & Estudo & Resultados Relevantes \\
\hline Barbosa et al. (2020)11455 & $\begin{array}{l}\text { Uso do checklist nos pontos } \\
\text { de verificação em um } \\
\text { abatedouro de bovinos }\end{array}$ & $\begin{array}{l}\text { Inspeção rotineira precária; falta de manual de boas práticas } \\
\text { de fabricação, o não uso dos procedimentos operacionais } \\
\text { padronizados e falta de treinamentos para os manipuladores. } \\
\text { Apresentando } 62,96 \% \text { dos itens avaliados estão não } \\
\text { conformes e } 23,46 \% \text { dos itens conformes. }\end{array}$ \\
\hline Silva et al. (2019) & $\begin{array}{l}\text { Avaliação das condições } \\
\text { higiênico-sanitárias } \\
\text { utilizando o checklist em um } \\
\text { abatedouro de aves }\end{array}$ & $\begin{array}{l}\text { Apresentou } 92,8 \% \text { dos itens avaliados em conformidade. } \\
\text { Porém o item de condições de higiene dos manipuladores e } \\
\text { a não utilização de uniforme branco pelos operários, são } \\
\text { itens que não estavam conformes. }\end{array}$ \\
\hline Dantas et al. (2017) & $\begin{array}{l}\text { Utilização do checklist } \\
\text { para a avaliação da condição } \\
\text { higiênico-sanitária } \quad \text { de } \\
\text { frigorífico de produtos } \\
\text { cárneos }\end{array}$ & $\begin{array}{l}\text { Os vinte abatedouros avaliados apresentaram deficiência } \\
\text { limpeza; uso comum da área de manipulação do alimento. } \\
\text { Sendo } 11,87 \% \text { de itens conformes e } 88,13 \% \text { de itens não } \\
\text { conformes, presente no terceiro frigorífico da cidade de } \\
\text { Pombal, PB. }\end{array}$ \\
\hline
\end{tabular}

Os oito abatedouros não possuíam forros nas suas

Uso do checklist para a

Oliveira (2017) avaliação da condição higiênico- sanitária de um abatedouro de bovinos instalações; presença de esterilizadores em um único abatedouro; os manipuladores não possuíam hábitos higiênicos regulares. Apresentando a média de $23,70 \%$ de conformidades nos abatedouros e o quarto abatedouro foi classificado como alto risco, com $21,22 \%$. 


$\begin{array}{ll} & \text { Uso do checklist } \\ & \text { nos pontos de verificação } \\ & \text { em um abatedouro } \\ \text { Moura et al. (2015) } \quad \text { de bovinos }\end{array}$

Uso do checklist

Os manipuladores não apresentavam práticas de higiene adequadas; a estrutura física dos cinco abatedouros apresentou-se não conforme. Um abatedouro considerado bom (E - 66,6\% de conformidade), um considerado regular (B- $50 \%$ de conformidade) e três foram considerados ruins (A $33,3 \%, \mathrm{C}-33,3 \%$ e $\mathrm{D}-8,3 \%)$.

Fonte: Autores.

Na tabela anterior (Tabela 2) é importante observar os resultados obtidos por algumas publicações nacionais recentes, que utilizaram o checklist para verificação das condições higiênico-sanitárias em abatedouros frigoríficos. Indicando através das porcentagens, que a maioria dos itens verificados nos estabelecimentos estão em não conformidade, como à falta de manual de boas práticas e de treinamentos para os funcionários, sem condição de higiene dos manipuladores, deficiência na limpeza, ausência de forro nas instalações. Fazendo com que o produto final seja comprometido (Filho et al, 2020).

\subsection{O uso da análise de swabs para avaliação higiênico-sanitária nos abatedouros}

Outra maneira de analisar as condições higiênico-sanitárias é através de swabs, onde os utensílios, equipamentos e carcaças são submetidos à análise de contagem padrão de microrganismos, que vão refletir as condições higiênico-sanitárias presentes no estabelecimento (Silva et al., 2019).

É uma técnica de esfregaço, que consiste na remoção do microrganismo, friccionando um cotonete estéril e umedecido em água peptonada, na superfície avaliada, utilizando um molde estéril que delimita a área amostrada, com passagens sucessivas e mudando de direção. O diluente é examinado por plaqueamento de alíquotas em meio de cultura apropriado. É uma metodologia padrão de análise microbiológica pela Amerian Public Health Association - APHAA, porém um dos inconvenientes desta técnica é o tempo necessário quando é utilizado o diagnóstico por microbiologia (Stocco et al., 2016).

Atualmente a Agência Nacional de Vigilância Sanitária (ANVISA) dispõe em vigência a Resolução da Diretoria Colegiada (RDC) no 331/2019, que estabelece padrões microbiológicos sanitários para alimentos, que vão auxiliar na interpretação e conclusão de resultados de análises microbiológicas. No entanto, é fundamental ter uma regulamentação que estabeleça padrões nacionais microbiológicos para as mãos de manipuladores, de superfícies de bancadas e utensílios, uma vez que esses estão em contato direto ou indireto com o alimento e podem vir a ser meios de contaminação aos alimentos (Nogueira, 2016).

A seguir, na Tabela 3, podemos observar os trabalhos recentes publicados e seus resultados relevantes com relação à verificação das condições higiênico sanitárias nos estabelecimentos abatedouros a partir da utilização do swab como ferramenta. 
Tabela 3. Publicações nacionais recentes com a utilização de análise de swab para verificação das condições higiênicosanitárias em abatedouros frigoríficos.

\begin{tabular}{|c|c|c|}
\hline Autor, ano & $\begin{array}{c}\text { Análises microbiológicas } \\
\text { realizadas }\end{array}$ & Resultados obtidos \\
\hline Silva et al. (2019) & $\begin{array}{l}\text { Bactérias mesófilas, } \\
\text { Enterobactérias }\end{array}$ & $\begin{array}{l}\text { De dez pontos analisados, } 90 \% \text { estavam acima } \\
\text { do limite preconizado para mesófilas. Em quatro } \\
\text { amostras foram detectadas acima do limite e E. coli } \\
\text { variando de } 2,0 \times 10^{2} \text { a } 7,7 \times 10^{4} \mathrm{UFC} / \mathrm{cm}^{2} \text {. }\end{array}$ \\
\hline Almeida et al. (2017) & $\begin{array}{l}\text { Escherichia coli } \\
\text { Salmonella spp }\end{array}$ & $\begin{array}{l}\text { Presença de } 40 \% \text { de Escherichia coli e Salmonella } \\
\text { spp. }\end{array}$ \\
\hline Barreto (2017) & $\begin{array}{l}\text { Aeróbios mesófilos } \\
\text { Enterobactérias }\end{array}$ & $\begin{array}{l}\text { Presença de } 75,54 \% \text { de aeróbios mesófilos e } \\
88,96 \% \text { de enterobactérias. }\end{array}$ \\
\hline Moura et al. (2015) & $\begin{array}{l}\text { S. aureus } \\
\text { Enterobactérias }\end{array}$ & $\begin{array}{l}\text { Frequência de } S \text {. aureus nas seguintes variáveis: } \\
88 \% \text { em utensílios, } 90 \% \text { nas mãos de } \\
\text { manipuladores e } 84 \% \text { nas carcaças. De } \\
\text { enterobactérias: } 24 \% \text { em utensílios, } 12 \% \text { nas mãos } \\
\text { dos manipuladores, } 28 \% \text { nas carcaças. }\end{array}$ \\
\hline
\end{tabular}

Fonte: Autores.

A Tabela 3, expressa os resultados obtidos através das análises microbiológicas realizadas com o uso do swab como ferramenta de coleta. Relata que nos abatedouros frigoríficos, estudados e presentes em publicações nacionais recentes, foi detectado a presença de bactérias mesófilas aeróbias, enterobactérias, Salmonella spp e S. aureus. Sendo que a Salmonella spp. é um dos patógenos com maior presença em doenças de origem alimentar e juntamente com o S. aureus são os agentes etiológicos mais identificados nos surtos de doenças transmitidas por alimentos (Ribeiro et al., 2018).

\subsubsection{Microrganismos indicadores de higiene}

Os microrganismos indicadores de higiene são aqueles que quando estão presentes nos alimentos podem fornecer dados sobre a presença de patógenos, a capacidade de deterioração do alimento, contaminação fecal, indicando as condições sanitárias impróprias durante o processamento, produção ou armazenamento do produto (Neto \& Rosa, 2014).

Alguns critérios devem ser considerados na definição de um grupo de microrganismos indicadores como: estar presente em números elevados nas fezes; ser distinguido de forma clara de outros microrganismos da microbiota do alimento; modo de crescimento equivalente às dos patógenos; proporção de morte paralela a dos patógenos de interesse; existente quando o patógeno associado estiver; não deve estar presente como contaminante natural do alimento; ter como habitat exclusivo o trato intestinal do homem e outros animais; ter alta resistência ao ambiente extra-enteral; ser facilmente detectável e deveria haver técnicas rápidas, simples e precisas para sua detecção e contagem (Costa, 2018).

De acordo com a Comissão Internacional de Especificações Microbiológicas para Alimentos (ICMSF), os microrganismos indicadores podem ser divididos nos que não oferecem risco à saúde (contagem padrão de mesófilos e contagem de bolores e leveduras, contagem de psicrotróficos e termófilos) e os microrganismos que oferecem um baixo risco à saúde (Coliformes a $45^{\circ} \mathrm{C}$, Coliformes totais, Enterobactérias totais, Enterococos, Escherichia coli) (Souza et al., 2014). 


\subsubsection{Mesófilos aeróbios}

A contagem padrão de microrganismos aeróbios mesófilos tem sido utilizada como um dos indicadores microbiológicos de qualidade. Este grupo possui importância por serem indicadores das condições inadequadas de produção, conservação e transporte. É uma contagem genérica para microrganismos que crescem aerobicamente ou facultativamente em temperaturas que variam entre $15^{\circ} \mathrm{C}$ a $45^{\circ} \mathrm{C}$. E a contagem alta de mesófilos indica condições favoráveis para a multiplicação de patógenos (Filho et al., 2015).

O grupo dos aeróbios mesófilos é formado por microrganismos da família Enterobacteriaceae, além de representantes dos gêneros clostridium, bacillus, streptococcus e corynebacterium, entre outros. Algumas bactérias patogênicas de origem alimentar pertencem ao grupo dos mesófilos, onde uma alta contagem de microrganismos indica desinfecção, limpeza e temperatura inadequadas durante o processo (Prado et al., 2019).

Segundo Rodrigues (2019), os mesófilos aeróbicos e enterobactérias são indicadores de condições higiênicosanitárias, mas a contagem de enterobactérias é mais específica que a contagem total de aeróbios mesófilos, levando em consideração a sua relação com a presença de Escherichia coli e a capacidade de desenvolver intoxicações alimentares e infecções.

No dizer de Costa (2018), níveis de contaminação por aeróbios mesófilos menores que $10^{5} \mathrm{UFC} / \mathrm{cm}^{2}$ da carcaça indicam boas condições de higiene durante o abate. Em níveis maiores de $10^{6} \mathrm{UFC} / \mathrm{cm}^{2}$ significa o início de processo de deterioração.

No entanto, na legislação brasileira não há parâmetros microbiológicos oficiais para superfícies dos equipamentos, mãos e luvas de manipuladores de alimentos. Por conta disso, as empresas habilitadas à exportação seguem os requisitos dos mercados destino. Porém, no Brasil, o Ministério da Saúde, por meio da Agência Nacional de Vigilância Sanitária (ANVISA), e o Ministério da Agricultura vêm sistematicamente definindo leis que visam à proteção do consumidor (Silva et al., 2019).

\subsubsection{Enterobactérias}

A família Enterobacteriaceae é formada por bacilos gram-negativos, aeróbios e anaeróbios facultativos, oxidase negativa, fermentadores de glicose e produtores de catalase e geralmente são nitrato redutores. Apresentam motilidade através de flagelos ou não apresentam motilidade (Oliveira et al., 2015). Os gêneros mais conhecidos desta família são Enterobacter, Citrobacter, Escherichia, Salmonella (Rodrigues, 2019).

As enterobactérias são encontradas na água, no solo, em plantas, produtos de origem animal e vegetal, insetos e no homem. Algumas das espécies de bactérias pertencentes a esta família são patogênicas para animais e plantas, causando perdas econômicas relevantes na agricultura e na indústria de alimentos (Almeida et al., 2017).

Outras espécies de enterobactérias são patogênicas para o homem, resultando em riscos para a saúde pública (Cê, 2016). Segundo o informe do Ministério da Saúde (2018) sobre os surtos de doenças transmitidas por alimentos no Brasil, os cinco agentes etiológicos mais identificados nos surtos de DTAs no período de 2009 a 2018 foram Escherichia coli (23,4 \%), Salmonella spp. (11,3\%), Staphylococcus aureus $(9,4 \%)$, coliformes $(6,5 \%)$ e norovírus $(3,9 \%)$.

A presença de Enterobacteriaceae é utilizada para avaliar as condições higiênico-sanitárias, sendo que uma contagem alta demonstra indícios de contaminação microbiana, por falhas na sanitização e na limpeza. O limite de concentração esperado e preconizado é de até $1,5 \log \mathrm{UFC} / \mathrm{cm}^{2}$, sendo que a sua quantificação indica uma possível contaminação fecal (Barreto, 2017; Costa, 2017).

Certas espécies de enterobactérias psicrotróficas surgem na carne refrigerada e são capazes de se multiplicar de forma aeróbica no tecido adiposo e muscular e seu desenvolvimento é favorecido em temperaturas superiores ou iguais a $4^{\circ} \mathrm{C}$. Outras 
se multiplicam na carne em atmosfera modificada ou embalada a vácuo quando estocada em temperaturas superiores a $10^{\circ} \mathrm{C}$ (Stocco et al., 2016).

Se apenas uma categoria de microrganismos indicadores deve ser eleita para o monitoramento das condições higiênico-sanitárias, a família Enterobacteriaceae deve ser escolhida em razão de sua relação com a presença de Escherichia coli e sua distribuição no ambiente (Barreto, 2017).

A Escherichia coli é uma bactéria pertencente à família Enterobacteriaceae, gram negativa, anaeróbica facultativa, forma de bacilo, natural da flora intestinal. Microrganismo que habita do trato intestinal de animais endotérmicos e humanos, mas, sendo conduzido para a circulação sanguínea, pode causar doenças e infecções no organismo hospedeiro. As cepas da bactéria podem ser adquiridas pela ingestão de alimentos ou de água contaminados, pelo contato com animais que possam estar contaminados (Nespolo et al., 2014).

As formas de infecções causadas por E. coli irão depender da cepa e de sua patogenicidade, o estado imunológico do infectado e a idade. As toxinas eliminadas estão associadas a casos de diarreias, septicemias e meningite nos humanos, sendo um microrganismo importante para a saúde pública (Almeida et al., 2017).

A E. coli é considerada a enterobactéria mais encontrada na carne e sua contaminação ocorre, na maioria das vezes, durante o abate, pelo contato da pele do animal com resíduos de fezes. A higiene incorreta dos utensílios e equipamentos utilizados no processo industrial, assim como as mãos dos colaboradores, são fatores importantes que contribuem com o aumento da contagem de microrganismos deteriorantes e patogênicos nas amostras de carne após a manipulação (Oliveira et al., 2015).

Dentre essas bactérias da família Enterobacteriacea, outra de significativa importância é Salmonella spp., sendo as aves, os suínos e os ovinos considerados meios de transmissão de salmoneloses para humanos (Reis et al., 2019).

A Salmonella spp. é um dos patógenos com maior envolvimento com doenças de origem alimentar (Brasão et al., 2019). Segundo Stocco et al. (2016), possui tolerância de sal superior a $9 \%$, temperatura ideal entre 35 e $37{ }^{\circ} \mathrm{C}$ e pH em torno de 7,0. Vários alimentos podem ser contaminados com Salmonella spp., principalmente os que possuem alto teor de proteína, umidade e carboidratos, ressaltando a carne bovina, aves, suína e outros alimentos suscetíveis a deterioração (Bortoluzzi et al., 2017).

As doenças provocadas pela ingestão de alimentos contaminados por este patógeno são a febre tifoide causada pela Salmonella typhi, a Salmonella paratyphi ocasiona as febres entéricas e as salmoneloses que são provocadas por outras salmonelas (Lima et al., 2019).

\subsubsection{Bolores e leveduras}

Os bolores e leveduras também são responsáveis por doenças alimentares, por causa da possibilidade de ocorrer o crescimento de determinadas espécies, que podem produzir toxinas fúngicas encontradas na superfície dos alimentos, quando o armazenamento e as condições de conservação são inadequados (Leão et al., 2015).

Os bolores podem produzir metabólitos tóxicos que são chamados de micotoxinas e são frequentes os gêneros Aspergillus spp., Penicillium spp. e Fusarium spp. Ao serem ingeridos quando estão presentes nos alimentos, causam alterações desfavoráveis ao homem e aos animais e algumas leveduras podem causar reações alérgicas (Reis, 2019).

Os bolores são formados por filamentos chamados de hifas. Possuem capacidade de adaptação e crescimento sob condições variáveis como a umidade e a temperatura entre $25^{\circ} \mathrm{C}$ e $30^{\circ} \mathrm{C}$, porém muitas espécies se desenvolvem em temperaturas de refrigeração entre $4^{\circ} \mathrm{C}$ e $5^{\circ} \mathrm{C}$ ou abaixo de $0^{\circ} \mathrm{C}$. São poucos exigentes quanto aos nutrientes disponíveis, razão pela qual o crescimento pode ocorrer em qualquer tipo de substrato. Um dos pontos positivos é que esses microrganismos podem ser usados para produzir antibiótico penicilina, queijos e outros produtos (Rodrigues et al., 2015). 
As leveduras, como os bolores, são fungos, contudo estes se diferenciam por ter uma forma de esférica a ovóide e de elipse a filamentosa. Por serem células simples, as leveduras crescem e se reproduzem mais rápido do que os bolores (Oliveira et al., 2017). Alguns fatores contribuem para a proliferação de leveduras nos alimentos como o ph ácido na faixa entre $4,0 \mathrm{e}$ 4,5 , temperatura ao redor de $25^{\circ} \mathrm{C}$ a $28^{\circ} \mathrm{C}$, embora muitas espécies se desenvolvam sob-refrigeração a $4^{\circ} \mathrm{C}$ e $5^{\circ} \mathrm{C}$ (Leão et al., 2015).

Sendo assim, a presença de leveduras e bolores em um índice alto nos alimentos pode fornecer muitas informações, como condições higiênicas inadequadas dos equipamentos, falha no processamento ou armazenamento e matéria prima contaminada (Reis, 2019).

\subsubsection{Impactos da contaminação microbiológica em produto de origem animal}

Os microrganismos presentes na carne podem ter origem do próprio animal, ou podem ser pela contaminação durante as etapas de abate e através da manipulação da carne. A contaminação pode ser determinada pela higiene das instalações do abatedouro, higiene do animal ante-mortem, pelas temperaturas usadas durante o processamento, nos locais de armazenamento e estocagem dos produtos finais, ou através da ocorrência de contaminação cruzada (Sales et al., 2014).

A presença desses microrganismos é um problema para a saúde humana, como visto no tópico de microrganismos indicadores de higiene, mas também representa um problema de caráter econômico quando se considera a deterioração causada por alguns grupos de microrganismos. A deterioração é um conjunto de sinais de crescimento microbiano, gerando como consequência odores fétido, alteração do sabor, mudança de coloração para um aspecto repugnante e transformação na superfície da carne (Costa, 2017). A presença de microrganismos deteriorantes em carnes é inevitável, o seu número deve ser controlado, enquanto os patogênicos devem ser evitados (Soares et al., 2015).

Os principais gêneros que causam a deterioração em carnes são: Acinetobacter, Pseudomonas, Moraxella e Aeromonas. Esses microrganismos utilizam a carne como substrato para realização de atividades metabólicas. O seu desenvolvimento em carnes acontece porque esta apresenta condições intrínsecas favoráveis como alta atividade de água nos tecidos, pH próximo ao neutro, elevado teor de nutrientes (Costa, 2017).

Em relação ao aparecimento de odores desagradáveis e mudanças no sabor, tal fato ocorre devido à grande quantidade de microrganismos, os quais podem esgotar o teor de glicose na carne, devido a sua utilização. Por conta disso, as bactérias utilizam a carne como fonte, através da degradação de aminoácidos, tendo como resultado a formação de metabólitos como aminas, amônia, aldeídos, compostos sulfurados e cetonas, que vão gerar sabor e odor desagradável (Dias-Barbosa et al., 2020).

$\mathrm{O} \mathrm{pH}$ da carne tende a se tornar alcalino devido à formação dos compostos, o que favorece o crescimento de microrganismos. Com o esgotamento dos carboidratos simples, o odor pode ou não se tornar perceptível, dependendo da quantidade de aminoácidos livres que foram utilizados (Sales et al., 2014).

A formação do limo superficial também pode ocorrer, durante a deterioração, formando substâncias viscosas, que surgem a partir de polissacarídeos sintetizados pelas bactérias. Podem ocorrer alterações na coloração da carne, por causa da produção de metabólitos microbianos, como $\mathrm{H} 2 \mathrm{~S}$ ou $\mathrm{H} 202$, que quando reagem com a mioglobina, produzem a sulfomioglobina e a coleglobina, que provocam o esverdeamento da carne (Moura et al., 2015).

\section{Conclusão}

Manter as condições higiênico-sanitárias em abatedouro frigorífico de bovinos, suínos ou de aves é de fundamental importância para que seja obtido um produto cárneo de alta qualidade. Para isso, existem os órgãos fiscalizadores que possuem um papel de relevância no controle e na verificação dos programas de autocontrole que são implantados e garantem um 
ambiente seguro, minimizado a contaminação da carcaça e do local. Os funcionários também possuem uma função essencial no controle da qualidade, assegurando as boas condições durante o processo.

Por fim, sugere-se que seja feita a implementação da cultura de segurança de alimentos nas empresas, para que se torne um valor para a organização, fazendo com que diminua as falhas de boas práticas, que em sua maioria envolvem o comportamento humano. E que através do uso do checklist e swabs, que verificam as condições higiênicas do abatedouro, o estabelecimento aplique medidas corretivas, para que se adquira um produto inócuo, de qualidade e seguro para os consumidores.

\section{Referências}

Abreu, A. M. T., Clemente, A. K. V., Barros, Y. V. R., Ferreira Junior, G.C., \& Souza, E. C. (2018). Análise dos surtos de origem alimen tar notificados no Brasil no período de 2015 a 2017. Higiene Alimentar, 32(285), 28-32.

Abujamra, T., Junior, A. S. F., Prado, N. F. O., Ramirez-Fernadez, F. J., \& Starikoff, K. R. (2017). Percepção dos consumidores em relação à segurança dos alimentos cárneos no município de Jataí-GO. Segurança Alimentar e Nutricional, Campinas, 1(24), 9 16. https://doi.org/10.20396/san.v24i1.8648081

Alexandrino, S. L. de S. A., Santos, T. L. S., Moraes, R. C., Gonçalves, L. F., Paula, L. C. de., Silva, G. de S. e., Minafra, C. S., \& Gomide, A. P. C. (2020). Qualidade, avaliação e tipificação de carcaças das principais espécies de interesse zootécnico: bovina, suína e aves. Research, Society and Development, [S. 1.], 9(10), 1-25. https://doi.org/10.33448/rsd-v9i10.8422.

Almeida, L., Walus, C., Bittencourt, J. M., \& Picinin, C. T. (2017). Frequência de contaminação microbiológica em frigorífico. Revista Brasileira de Tecnologia Agroindustrial, [S.1.], 11(1), 2314-31. https://doi.org/10.3895/rbta.v11n1.5162

Barreto, E. H. (2017). Controle da qualidade sanitária em frigorífico de suínos do Paraná. Dissertação de mestrado, Universidade Tecnológica Federal do Paraná, Ponta Grossa, PR, Brasil.

Bortoluzzi, D. S., Pavanelli, M. F., \& Braga, L.S. (2017). Avaliação microbiológica de Salmonella spp. nos alimentos produzidos em um abatedouro de aves. Revista Iniciare, Campo Mourão, 2 (1), 10-20.

Brasão, S. C., Melo, R. T., Mendonça, E. P., Monteiro, G. P., \& Rossi, D. A. (2019). Ação de diferentes sanitizantes em biofilmes de Salmonella Minnesota. Higiene Alimentar, [S.1.], 33 (288/289), 2251-55.

Brasil. (1995). Ministério da Agricultura, Pecuária e Abastecimento. Portaria $\mathrm{N}^{\circ}$ 711, Normas Técnicas de Instalações e Equipamentos para Abate e Industrialização de Suínos, de $1^{\circ}$ de Novembro de 1995. Diário Oficial da União, Brasília, Sec. I, p. 17625.

Brasil. (1998). Portaria n. 210 de 10 de novembro de 1998. Regulamento técnico da inspeção tecnológica e higiênico-sanitária de carne de aves. Diário Oficial [da] República Federativa do Brasil, Poder Executivo, Brasília, DF, 26 nov. 1998.

Brasil. (2018). Surtos de Doenças Transmitidas por Alimentos no Brasil. Ministério da Saúde. Secretária de Vigilância em Saúde. Coordenação geral de doenças transmissíveis. www.saude.gov.br/svs.

Cê, E. R. (2016). Influência das etapas do processo de abate de suínos na prevalência de patógenos e níveis de microrganismos indicadores de qualidade e higiene. Dissertação de Mestrado, Universidade Tecnológica Federal do Paraná Programa de Pós Graduação em Tecnologia de Alimentos, Londrina, PR, Brasil.

Costa, L. R. M. (2018). Relação entre a sujidade visual da pele de bovinos e contaminação microbiológica da carcaça em dois pontos da linha de abate em um abatedouro frigorífico de Uberlândia - MG. Trabalho de conclusão de curso (TCC) em Medicina Veterinária, Universidade Federal de Uberlândia, Uberlândia, MG, Brasil.

Costa, P. H. G. (2017). Associação entre a sujidade da pele de bovinos e contaminação cruzada em um abatedouro-frigorífico da região do triângulo mineiro, Minas Gerais. Trabalho de conclusão de curso (TCC) em Medicina Veterinária, Universidade Federal de Uberlândia, Uberlândia, MG, Brasil.

Dantas, R. P., Silva, E. V., Araújo, A. S., Paiva, Y. F., Sousa, T. C. A., \& Neto, M. S. M. (2017). Avaliação das condições higiênico-sanitárias de frigoríficos do sertão paraibano. Revista Brasileira de Gestão Ambiental, Pombal, 11(2), 25-31.

Dias, I. C. L. (2012). Prevenção de zoonoses ocupacionais em abatedouros de bovinos. Vivências: Revista Eletrônica de Extensão da URI, 8(15), 89-98.

Dias-Barbosa, C. Z. M. C., Araújo, I. S., \& Luz, R. G. L. P. (2020). Condições físicas e higiênico-sanitária do matadouro público de São João dos Patos MA. Brazilian Journal Of Development, 6(4), 19815-24. https://doi.org/10.34117/bjdv6n4-231

Filho, C. S. C., Silva. E. O., Silveira-Filho, V. M., \& Castanha, E. R. (2015). Avaliação microbiológica de bactérias aeróbias mesófilas no leite in natura produzido em uma associação rural em Garanhuns-PE. Revista Brasileira de Agrotecnologia, 5(1), 87-93.

Filho, J. L. P., Neto, P. S. G., Ferreira, J. M. S., Monteiro, P. M., Lima, A. M. L. (2020). Avaliação das condições higiênico-sanitárias de alimentos comercializados no Mercado Central em São Luís - MA. Research, Society and Development, 9(7), 1-15. https://doi.org/10.33448/rsd-v9i7.4584

Fonseca, W., Moreno, B. F. S. (2018). Comida de rua: conhecimento dos consumidores sobre a segurança dos alimentos e condições higienicossanitárias de pontos de venda em São Luís, MA. Higiene Alimentar, 32(264/265), 61-65. 
Formigoni, A. S., Marcelo, G. C., \& Nunes, A. N. (2017). Importância do programa de qualidade - boas práticas de fabricação (BPF) na produção de ração. Nutritime, 14(6), 8016-25.

Forsythe, S. J. (2013). Microbiologia da segurança dos alimentos. (2a ed.). Artemed, 602p.

Fruet, A. P. B., Stefanello, F. S., Kirinus, J. K., Pelegrini, L. F., Nörnberg, J. L., \& Dörr, A. C. (2014). Legislação e implementação dos programas de controle de qualidade em frigoríficos sob fiscalização federal no Brasil. PUBVET, Londrina, 8(13), 1551-1697.

Garnett, T. (2013). Food sustainability: problems, perspectives and solutions: problems, perspectives and solutions. Proceedings Of The Nutrition Society, 72(1), 29-39. https://doi.org/10.1017 / S0029665112002947

Guerra, J. R. N. P. (2015). Identificação de perigos na cadeia de produção e distribuição de produtos comercializados por uma Empresa do ramo alimentar. Dissertação de Mestrado, Universidade de Nova Lisboa, Lisboa, Portugal.

Leão, S. C., Barreto, D. M., Ribeiro, V. C., Santana, R. F., Melo, C. M., Lima, A. S., \& Batista, M. V. A. (2015). Qualidade Microbiológica e Parasitoló gica da Carne Moída Comercializada em Aracaju/SE. Brazilian Journal Of Food Research, 6(2), 15-22. https://doi.org/10.14685/rebrapa.v6i2.3484

Lima, L. A., Silva, F. B., Silva, F. B., Dias, M., Stella, A. E., \& Junqueira, O.M. (2019). Manejo sanitário de aviário de pequeno porte de frangos de corte e presença de Salmonella sp. Higiene Alimentar, 33(288/289), 1923-27.

Machado, R. L. P., Dutra, A. S., \& Pinto, M. S. V. (2015). Boas práticas de fabricação (BPF). Rio de Janeiro, Embrapa Agroindústria de Alimentos, 2015, 15, 540-544.

Martins, L. G., Barreto, V. C. C. (2018). Avaliação das condições higiênicossanitárias de padarias no município de Cabo de Santo Agostinho, PE. Higiene Alimentar, 32(285/286), 50-54.

Mateus, K., Santos, M. R., Cardoso, G. J., Souza, A. T., \& Kessler, J. D. (2017). A importância e benefícios da carne na alimentação. Jornal Sul Brasil, Santa Catarina, 18, 10-12.

Melo, E. S., Amorim, W. R., Pinheiro, R. E. E., Corrêa, P. G. N., Carvalho, S. M. R., Santos, S. R. S. S., Barros, D. S., Oliveira, E. T. A. C., Mendes, C. A., \& Sousa, F. V. (2018). Doenças transmitidas por alimentos e principais agentes bacterianos envolvidos em surtos no Brasil: revisão. Pubvet, 12(10), 1-9. https://doi.org/10.31533/pubvet.v12n10a191.1-9

Mendonça, A. T. A. (2019). Bem estar animal: Conceitos, importância e aplicabilidade para animais de companhia e de produção. Monografia (Especialização) em Medicina Veterinária, Universidade Federal Rural da Amazônia, Belém, Brasil.

Moura, E. S. R., Abrantes, M. R., Mendes, C. G., Oliveira, A. R. M., Sousa, E. S., \& Silva, J. B. A. (2015). Perfil higiênico-sanitário e perigos microbiológicos em abatedouros públicos. Revista Brasileira de Medicina veterinária, Rio de Janeiro, 37(3), 203-208.

Nespolo, N. M., Saba, R. Z., Rossatelli, D. A., \& Fairbrother, J. M., Júnior, O. D. (2014). Ocorrência de Escherichia coli O157: h7 e o26 sorbitol negativas em matadouro frigorífico de bovino e suscetibilidade a antimicrobianos: $\mathrm{H} 7$ e $\mathrm{O} 26$ sorbitol negativas em matadouro frigorífico de bovino e suscetibilidade a antimicrobianos. Arquivos do Instituto Biológico, 81(3), 209-17. https://doi.org/10.1590/1808-1657001332012

Neto, A. C., Rosa, O. O. (2014). Determinação de microrganismos indicadores de condições higiênicas sanitárias nas mãos de manipuladores de alimentos. Revista Brasileira de Tecnologia Agroindustrial, 8(1), p. 1251-61. http://dx.doi.org/10.3895/S1981-36862014000100010

Nogueira, J. P. (2016). Análise microbiológica de superfícies de manipulação de alimentos em cantinas de uma Universidade Pública. Trabalho de conclusão de curso (TCC) em Nutrição, Universidade Federal do Rio Grande do Norte, Natal, RN, Brasil.

Nunes, S. M., Novella, M. C. C., Tiba, M. R., Bento, C. A. Z. I. S. S., Paschualinoto, A. L., Thomaz, I., \& Walendy, C. H. (2017). Surto de doença transmitida por alimentos nos municípios de Mauá e Ribeiro Pires - SP. Higiene Alimentar, 31(264/265), 97-102.

Oliveira, M. S., Sousa, V. C., Oliveira, C. P., Nunes, G. S., Natylane, E. F., Machado, F. C. F., Machado Júnior, A. A. N. (2017). Qualidade físico-química e microbiológica da carne moída de bovino em açougues. Revista Electrónica de Veterinaria, 18(12), 1-13.

Oliveira, M.A., Takamura, A. E., Vigoya, A. A. A., \& Araújo, F. (2015). Enterobacteriaceae: bactérias intestinalis de organismos aquáticos, um risco à saúde pública - Revisão de literatura. Revista Científica de Medicina Veterinária, 25(28), 1-20.

Oliveira, N. C. T. (2017). Avaliação higiênico-sanitária de abatedouros com sistema de inspeção municipal no semiárido nordestino. Dissertação de Mestrado em Zootecnia, Universidade Federal de Campina Grande, Patos, PB, Brasil.

Oliveira, N. T., Campos, R. M. L. (2015). Utilização das ferramentas de gestão de qualidade em frigorífico de abate de bovinos para exportação. Nutritime, 12(2), 4016-29.

Pereira, A. S., Shitsuka, D.M., Parreira, F. J. \& Shitsuka, R. (2018). Metodologia da Pesquisa Científica. UFSM NTE.

Peres, L. A. (2014). Boas práticas de fabricação em matadouro-frigorífico de bovinos. Monografia (Especialização) em Medicina Veterinária, Universidade Federal do Rio Grande do Sul, Porto Alegre, RS, Brasil.

Prado, S. J. C., Fontenelle, R. O. S., Coutinho, M. G. S., Silva, L. C., \& Neves, A. N. (2019). Avaliação microbiológica e parasitológica da água proveniente de chuvas armazenadas em cisternas localizadas em uma zona rural do município de Santana do Acaraú, CE. Revista Uningá, 56(3), 141-150.

Quintino, S. S., RODOLPHO, D. (2018). Um estudo sobre a importância do APPCC - Análise dos perigos e pontos críticos de controle na indústria de alimentos. Revista Interface Tecnológica, 15(2), 196-207. https://doi.org/10.31510/infa.v15i2.452

Ramos, G. V., Vilela, J. B. (2016). Implantação dos programas de autocontrole em Indústrias de alimento de origem animal. XII SEGET: Simpósio de Excelência em Gestão e Tecnologia Desenvolvimento de Competências Frente aos Desafios do Amanhã - Resende, RJ, 2(25),20-24. 
Reinehr, C. O., Klanovicz, N. C., Colla, L. M. (2014). Toxinfecções alimentares e estratégias de gestão da segurança dos alimentos. Higiene Alimentar, 28(230/231), 105-10

Reis, R. M. (2019). Qualidade de carne bovina moída in natura comercializada em Manaus, AM. Dissertação de Mestrado em Ciência Animal, Universidade Federal do Amazonas, Manaus, AM, Brasil.

Reis, V. R., Ping, F. O. C., \& Damalio, V. B. (2019). Pesquisa de Salmonella spp. em carne mecanicamente separada (CMS) de frango produzida em um abatedouro frigorífico sob inspeção federal no estado do Tocantins, Brasil. Higiene Alimentar, 33, (288/289), 1982-85.

Rodrigues, E. B., Araújo, A. M., Sobral, F. de O. S., \& Romão, N. F. (2015). Avaliação da presença de bolores e leveduras em farinha de mandioca (Manihot esculenta Cratz) comercializadas a granel em feiras livres do município de Ji-Paraná - RO. South American Journal of Basic Education, Technical and Technological, 2(2)15-22.

Rodrigues, J. C. F. (2019). Avaliação da qualidade higiênico-sanitária em abatedouro frigorífico de bovinos. Dissertação de Doutorado em Tecnologia de Alimentos, Instituto Federal de Educação, Ciência e Tecnologia Goiano - Campus Rio Verde, Rio Verde, 46 f.

Sales, L. E. M., Abrantes, M. R., Oliveira, A. R. M., Soares, K. M. P., Mendes, C. G., Leite, A. I., \& Silva, J. B. A. (2014). Avaliação da carne suína in natura comercializada em Mossoró-RN. Acta Veterinaria Brasilica, 7(4), 306-10. https://doi.org/10.21708/avb.2013.7.4.3489

Santos, R. L., Palma, J. M., \& Santana, A. P. (2017). Avaliação da qualidade higienicossanitária de carcaças de bovinos oriundos de abatedouros frigoríficos do Distrito Federal e entorno. Higiene Alimentar, 31(272/273), 80-83.

Silva, I. A. A., Barbosa, A. E. O., Santos, E. C., Silva, J. B. A., \& Abrantes, M. R. (2019). Avaliação microbiológica em abatedouro de aves nos estado do Rio Grande do Norte. In: I Encontro Potiguar de Medicina Veterinária, 86, Mossoró. Anais [...]. Mossoró: EdUFERSA, Mossoró, RN, Brasil.

Silveira, S. V., Garrido, \& L. R., Hoffann. (2015). Produção integrada de uva para processamento: processos de elaboração de sucos e vinhos, BPA e PPHO, Brasília, Embrapa, 30(1-2), 210-15

Soares, K. M. P., Silva, J. B. A., Souza, L. B., Mendes, C. G., Abrantes, M. R., Campelo, M. C. S., \& Souza, A. S. (2015). Qu alidade microbiológica de carne bovina comercializada na forma de bife. Revista Brasileira Ciência Veterinária, 22(3-4), 206-10. https://doi.org/10.4322/rbcv.2016.016

Sousa, J. S. (2018). A carne suína: Legislação, cortes e comércio (Uma revisão). Trabalho de conclusão de curso (TCC) em Medicina Veterinária, Universidade de Brasília, Brasília, DF, Brasil.

Souza, A. M. C., Maciel, T. L. S., Cabral, S., Zambi, B. A. A., Gomes, K. S., \& Bianch, I. Análise dos perigos e pontos críticos de controle em um matadouro-frigorífico de aves em Castelo, ES. Revista Dimensão Acadêmica, 2(1), 6-19.

Souza, G. C., Gonsalves, H. R. O., Gonsalves, H. E. O., Coêlho, J. L. S. (2014). Característica microbiológica da carne de frango. Acsa - Agropecuária Científica no Semi-Árido, 10(1), 12-17. http://dx.doi.org/10.30969/acsa.v10i2.353

Stocco, C. W., Almeida, L., Barreto, E. H., Bittencourt, J. V. M. (2016). Controle de qualidade microbiológico no processamento de frigorífico bovino. Revista Espacios, 38(22), 1-14.

Valeiro, N. V., Oliveira, A. P., Covre, L., Decol, C. M., Gonçalves, J. A. (2015). Avaliação da eficiência do PPHO de um matadouro frigorífico bovino de Rondônia - Estudo de caso. Enciclopédia Biosfera, Goiânia, 11(22), 408-16. http://dx.doi.org/10.18677/Enciclopedia_Biosfera_2015_094

Viana, F. J. C., Franklin, F. L. A. A., Pereira, C. F. C., Lima, D. B. C., Junior, A. M. C., \& Rizzo, M. S. (2014). Abate clandestino de suínos e pequenos ruminantes na cidade de Teresina, Piauí: implicações na saúde ocupacional. Rev. Int. Ciências e Saúde, Teresina, 1(1), 38- 47.

Wolf, C. (2017). Estudo de caso da higiene (limpeza e desinfecção) em matadouro-frigorífico de bovinos, suínos e ovinos. Monografia (Especialização) em Medicina Veterinária, Universidade Federal do Rio Grande do Sul, Porto Alegre, RS, Brasil. 